\title{
R \& D-Based Growth Model with Nominal Wage Stickiness
}

\author{
Shunsuke Shinagawa ${ }^{1}$, Tomohiro Inoue ${ }^{2}$ \\ ${ }^{1}$ Faculty of Economics, Kanagawa University, Yokohama, Japan \\ ${ }^{2}$ Faculty of Economics, Komazawa University, Tokyo, Japan \\ Email: shinagawa@kanagawa-u.ac.jp, inouetomo@gmail.com
}

How to cite this paper: Shinagawa, S. and Inoue, T. (2016) R \& D-Based Growth Model with Nominal Wage Stickiness. Theoretica Economics Letters, 6, 854-867. http://dx.doi.org/10.4236/tel.2016.65089

Received: July 26, 2016

Accepted: September 4, 2016

Published: September 7, 2016

Copyright $\odot 2016$ by authors and Scientific Research Publishing Inc. This work is licensed under the Creative Commons Attribution International License (CC BY 4.0).

http://creativecommons.org/licenses/by/4.0/ (c) (i) Open Access

\begin{abstract}
In this study, we introduce nominal wage stickiness into an endogenous growth model based on R \& D. This study examines how money growth affects long-run economic growth. We find that there exists a unique balanced growth path for sufficiently high rates of money growth, and that the economy exhibits sustained growth based on sustained R \& D. Faster money growth results in greater employment and faster economic growth along such a balanced growth path. Furthermore, under some parameter restrictions, no balanced growth path exists for low rates of money growth; the economy is trapped in a steady state without long-run growth. These results suggest that money growth may be an important factor for long-run economic growth.
\end{abstract}

\section{Keywords}

Endogenous Growth, New Keynesian Phillips Curve, Nominal Rigidities, Monetary Growth Theory

\section{Introduction}

This study proposes a new monetary growth model involving price stickiness and endogenous R \& D. Short-run macroeconomic models usually consider price stickiness, as in new Keynesian models. In this study, we introduce nominal wage stickiness into a long-run growth model based on R \& D and investigate how money growth affects long-run output, employment, and economic growth.

We base the dynamics of our model on the new Keynesian Phillips curve (NKPC), under which money is not super neutral, even in the long run ${ }^{1}$. [2] [3] proposed the Dynamic General Equilibrium (DGE) model with the NKPC and technological change, in which money is not super neutral in the long run and the long-run output gap exists when the monetary growth rate is below that of technological change. However, their

${ }^{1}[1]$ pointed out the importance of considering a non-vertical Phillips curve in macroeconomic models. 
analyses assumed exogenous technological change. This study proposes a DGE model based on the work of [2] with endogenous technological change rather than exogenous growth by introducing explicit $\mathrm{R} \& \mathrm{D}$ activities.

We focus on the steady-state economic growth and employment. For sufficiently high money growth rates, there is a unique balanced growth path, and the economy exhibits sustained growth based on sustained R \& D. Faster money growth causes greater employment and faster economic growth along the balanced growth path. Furthermore, under some parameter restrictions, there is no balanced growth path for low money growth rates, and the economy is trapped in a steady state without long-run growth. These results suggest that money growth may be an important factor for longrun economic growth. That is, financial authorities are required to maintain high money growth rates to achieve sustained and faster economic growth.

Most of the preceding theoretical studies on money and endogenous growth have concluded that a higher money growth is associated with a lower rate of long-run growth, which is contrary to the conclusion of this study. See for example [4]-[8]. In contrast, [9] [10] have demonstrated the positive relationship between a monetary expansion and long-run growth using the infinitely lived overlapping-generation models. Some studies such as [11]-[13] proposed endogenous growth models that introduced nominal rigidities. [11] investigated how the volatility of monetary policy affects output growth under price and wage stickiness. [12] studied optimal monetary policy by using an endogenous growth model with a sticky price due to Calvo pricing, and showed that the optimal steady-state inflation rate is zero. [13] proposed an endogenous growth model with sticky wage due to staggered Taylor wage contracts, and found a nonlinear relationship between money growth and long-run economic growth. In these studies, sustained growth becomes endogenous through learning-by-doing or simple externality, which differ from our study focusing on $\mathrm{R} \& \mathrm{D}$ as the engine of economic growth ${ }^{2}$. This study proposes a new channel attributed to nominal rigidities and endogenous $\mathrm{R} \& \mathrm{D}$ through which money growth influences the long-run economic growth.

Some empirical studies argued that inflation has a negative impact on economic growth ([15]-[17]). However, [18] [19] pointed out that the negative correlation between inflation and growth is not robust. [20] concluded that growth and inflation are negatively related only in the extremely high inflationary economy. Furthermore, a number of empirical studies showed positive relationships between inflation (or money growth) and economic growth for advanced countries. See for example [21]-[26] ${ }^{3}$. Our

${ }^{2}[14]$ have also proposed a new Keynesian endogenous growth model introducing human capital accumulations.

${ }^{3}[21]$ reported a positive correlation between real growth and money growth (M0, M1, and M2) for a subsample of OECD countries using the data for the period 1960-1990. [22] showed a positive and statistically significant correlation between money (M1 and M2) and real GDP growth rates as well as between CPI and real GDP growth rates for the OECD countries using the data for the more recent period 1960-1996. They also found a positive and significant correlation between the growth rates of M1 and real GDP for countries with inflation rates no greater than 15\%. [23] reported that the effects of inflation on economic growth are positive and significant when the inflation rate is below its threshold level of $15 \%-18 \%$ using the panel data for 80 countries over the period 1961-2000. [24] found that inflation is positively and significantly correlated with economic growth in industrial countries if the inflation rate is less than $2.53 \%$. [25] also found a positive growth effect of moderate inflation for advanced countries. [26] used a threshold regression model to investigate a relationship between inflation and economic growth for Japan using the data for the period 1970-2001. They showed that inflation promotes economic growth as long as inflation rate falls within the range between $2.52 \%$ and $9.66 \%$. 
study provides a theoretical explanation for these empirical results.

The remainder of this paper is organized as follows. Section 2 sets up the model used in our theoretical investigation. Section 3 derives the law of motion and the steady state, which characterize the equilibrium path of the economy. It also investigates the existence and the uniqueness of the steady state. Section 4 concludes the paper.

\section{Model}

We consider the continuous-time version of the dynamic model based on [2] [27]. Let us assume an economy populated by many infinitely-lived households under monopolistic competition in the labor market, and there are rigidities of nominal wage. There is a single final good, which is produced using intermediate goods and supplied competitively. A new variety of intermediate goods is invented by allocating labor for R \& D activities, and inventors enjoy infinitely-lived monopoly power. The available inter-mediate goods are produced by multiple intermediate firms using labor. Finally, we use the simple monetary policy rule under which financial authorities expand money supply at a constant rate.

\subsection{Employment Agency}

The manufacturing and R \& D sectors regard each household's labor as an imperfect substitute for any other household's labor. To simplify the analysis, we assume that an employment agency combines differentiated labor forces into a composite labor force according to the Dixit-Stiglitz function, $l=\left[\int_{0}^{1} l_{j}^{\zeta} \mathrm{dj}\right]^{\frac{1}{\zeta}}, \zeta \in(0,1)$, and supplies composite labor to the intermediate goods and the R \& D sectors. $l_{j}$ denotes differentiated labor supplied by household $j \in[0,1]$, and $l$ is the composite labor force. The number of households is normalized to $1 . v=1 /(1-\zeta)(>1)$ is the elasticity of substitution between each pair of differentiated labor inputs.

Cost minimization of the employment agency yields the demand functions for differentiated labor $j, l_{j}=\left(W_{j} / W\right)^{-\frac{1}{1-\zeta}} l$, where $W_{j}$ denotes the nominal wage rate of labor force $j$, and $W$ denotes the nominal wage rate of the composite labor force, which is given by $W=\left[\int_{0}^{1} W_{j}^{-\frac{\zeta}{1-\zeta}} d j\right]^{-\frac{1-\zeta}{\zeta}}$.

\subsection{Final Goods Sector}

We assume that perfect competition prevails in the final goods market. The final goods firm produces the quantity $y$ according to the Dixit-Stiglitz function,

$$
y=\left[\int_{0}^{N} x_{i}^{\alpha} \mathrm{d} i\right]^{\frac{1}{\alpha}}, \alpha \in(0,1)
$$

where $x_{i}$ is the quantity of intermediate goods indexed by $i \in[0, N]$, and $\phi=1 /(1-\alpha) \quad(>1)$ represents the elasticity of substitution between every pair of intermediate goods. $N$ is the number of available intermediate goods and represents the 
technology level of the economy. The final goods firm faces diminishing returns with each intermediate good; therefore, greater values of $N$ imply higher productivity.

Cost minimization by the final-goods producing firm yields the following demand functions for intermediate goods $i \in[0, N]$ :

$$
x_{i}=\left(\frac{p_{i}}{p}\right)^{-\frac{1}{1-\alpha}} y
$$

where $p_{i}$ is the price of intermediate goods $i$, and $p$ is the price of the final good or the price level, which is given by $p=\left[\int_{0}^{N} p_{i}^{-\frac{\alpha}{1-\alpha}} \mathrm{d} i\right]^{-\frac{1-\alpha}{\alpha}}$.

\subsection{Intermediate Goods Sector}

Each intermediate good is produced using one unit of composite labor; thus, marginal cost is equal to the nominal wage level, $W$. Because patents have an infinite life, all intermediate goods are supplied monopolistically. Maximization of the monopoly profit, $\Pi_{i}=\left(p_{i}-W\right) x_{i}$, subject to the demand function (1) yields

$$
p_{i}=p_{x} \equiv \frac{1}{\alpha} W, \quad x_{i}=x \equiv \frac{l_{x}}{N}, \quad \forall i \in[0, N],
$$

where $l_{x}$ represents the amount of composite labor allocated to the production of the intermediate goods. All intermediate goods enter symmetrically into production of the final good. Moreover, the maximized monopoly profit is

$$
\Pi_{i}=\Pi=\frac{1-\alpha}{\alpha} W x_{i}=\frac{1-\alpha}{\alpha} W \frac{l_{x}}{N}, \quad \forall i \in[0, N] .
$$

From (2), the market equilibrium levels of output, $y$, and the price of the final good, $p$, are obtained as

$$
\begin{gathered}
y=N^{\frac{1}{\alpha}} X=N^{\frac{1-\alpha}{\alpha}} l_{x}, \\
p=N^{-\frac{1-\alpha}{\alpha}} p_{x}=N^{\frac{1-\alpha}{\alpha}} \frac{1}{\alpha} W .
\end{gathered}
$$

We can rewrite (5) as $w \equiv W / p=\alpha N^{\frac{1-\alpha}{\alpha}}$.

\subsection{R \& D Sector}

The number of intermediate goods, $N$, expands according to the following equation:

$$
\frac{\dot{N}}{N}=\eta l_{n}, \quad N(0)>0,
$$

where $\eta(>0)$ is the parameter that reflects the productivity of R \& D. $l_{n}$ represents the amount of composite labor allocated to $\mathrm{R} \& \mathrm{D}$, and clearing the labor market requires $l=l_{x}+l_{n}$.

In equilibrium, the following free-entry condition must be satisfied:

$$
V \leq \frac{W}{\eta N} \text {, with an equality whenever } \dot{N}>0 \text {. }
$$


The right-hand side is the nominal unit cost of R \& D. $V$ represents the value of the patent, which is given by the discounted stream of the monopoly profit:

$$
V(t)=\int_{t}^{\infty} \Pi(\tau) \mathrm{e}^{-\int_{t}^{\tau} R(t) \mathrm{d} t} \mathrm{~d} \tau
$$

where $R$ is the nominal interest rate. Differentiating both sides with respect to time, $t$, yields the following no-arbitrage condition:

$$
R=\frac{\Pi+\dot{V}}{V}
$$

\subsection{Households}

Household $j$ possesses nominal money balances, $M_{j}$, and share of the monopoly firms, $S_{j}$. The share $S_{j}$ yields returns at rate $R$. Thus, the budget constraint of household $j \in[0,1]$ is given by

$$
\dot{A}_{j}=\dot{M}_{j}+\dot{S}_{j}=W_{j} l_{j}+R S_{j}-p c_{j}+p \tau
$$

where $A_{j}$ is the nominal assets of household $j, l_{j}$ is labor supplied elastically by household $j$, and $c_{j}$ is consumption of household $j . p \tau$ is nominal transfer income from the financial authorities in a lump-sum fashion. The final goods market clears when $y=c \equiv \int_{0}^{1} c_{j} \mathrm{~d} j$. We can rewrite the budget constraint in real terms as

$$
\dot{a}_{j}=\frac{W_{j}}{p} l_{j}+r a_{j}-R m_{j}-c_{j}+\tau,
$$

where $r \equiv R-\pi$ is the real interest rate, $\pi \equiv \dot{p} / p$ is the inflation rate, $m_{j} \equiv M_{j} / p$ is real money balances, and $a_{j} \equiv A_{j} / p$ is the stock of assets in real terms.

Household $j$ obtains utility from consumption, $c_{j}$, and real money balances, $m_{j}$, and it encounters disutility from the labor supply, $l_{j}$, and wage negotiations. Thus, the instantaneous utility function of household $j$ is

$$
u\left(c_{j}, m_{j}, l_{j}, \omega_{j}\right)=\log c_{j}+\delta_{m} \log m_{j}-\delta_{l} \frac{l_{j}^{1+\psi}}{1+\psi}-\frac{\gamma}{2} \omega_{j}^{2},
$$

where $\psi(>0)$ is the elasticity of the marginal disutility of the labor supply. $\gamma(\geq 0)$ denotes the scale of the nominal wage adjustment cost from wage negotiations and $\omega_{j} \equiv \dot{W}_{j} / W_{j}{ }^{4}$. If $\gamma=0$, the nominal wage is flexible; however, if $\gamma>0$, the nominal wage is sticky. $\delta_{m}(>0)$ and $\delta_{l}(>0)$ denote the utility weights on real money balances and labor supply, respectively.

Summarizing the above, household $j$ faces the following dynamical optimization problem:

$$
\begin{array}{ll}
\max _{c_{j}, m_{j}, \omega_{j}} & \int_{0}^{\infty}\left[\log c_{j}+\delta_{m} \log m_{j}-\delta_{l} \frac{l_{j}^{1+\psi}}{1+\psi}-\frac{\gamma}{2} \omega_{j}^{2}\right] \mathrm{e}^{-\rho t} \mathrm{~d} t, \\
\text { subject to } & \dot{a}_{j}=r a_{j}+\frac{W_{j}}{p} l_{j}-c_{j}-R m_{j}+\tau, \quad \dot{W}_{j}=\omega_{j} W_{j}, \quad l_{j}=\left(\frac{W_{j}}{W}\right)^{-\frac{1}{1-\zeta}} l,
\end{array}
$$

${ }^{\overline{4}}$ We specify the adjustment cost function as a quadratic expression following [28]. 
where $\rho(>0)$ is the subjective discount rate. Since all households behave symmetrically according to the same equations, $W_{j}=W, c_{j}=c, w_{j}=w, l_{j}=l$, and $m_{j}=m$ hold. When $\gamma>0$, the solution to the optimization problem above is characterized by the Euler equation and the wage version of the NKPC, as follows:

$$
\begin{aligned}
& \frac{\dot{c}}{c}+\rho+\pi=R=\delta_{m} \frac{c}{m}, \\
& \dot{\omega}=\omega \rho+\frac{\zeta}{1-\zeta} \frac{l w}{c \gamma}-\frac{\delta_{l}}{1-\zeta} \frac{l^{1+\psi}}{\gamma},
\end{aligned}
$$

where $m \equiv \int_{0}^{1} m_{j} \mathrm{~d} j$ is real money balances for the entire economy. The transversality condition for the households is given by $\lim _{t \rightarrow \infty}(a(t) / c(t)) \mathrm{e}^{-\rho t}=0$.

On the other hand, when $\gamma=0$ the following equation holds instead of the NKPC (9):

$$
\zeta \frac{w}{c}=\delta_{l} l^{\psi}
$$

\subsection{Money Growth}

Financial authorities are assumed to change money supply, $M$, at a constant rate $\theta$. That is, the financial policy rule is given by $\dot{M} / M=\theta$. Therefore, $\dot{m} / m=\theta-\pi$ holds. All seignorage is transfered to households; that is, $p \tau=\dot{M}$.

\section{Steady State}

When the nominal wage is sticky $(\gamma>0)$, and the positive composite labor is allocated to $\mathrm{R} \& \mathrm{D}$ at any time $\left(l_{n}>0\right)$ the equilibrium path is characterized by the transversality condition and the following differential equations:

$$
\begin{gathered}
\dot{R}=R^{2}-(\theta+\rho) R, \\
\dot{\chi}=R \chi-(\rho+\omega) \chi, \\
\dot{\omega}=\rho \omega+\left(\frac{l}{\chi}-\delta_{l} l^{1+\psi}\right) \frac{v}{\gamma},
\end{gathered}
$$

where $\chi \equiv I_{x} /(\alpha \zeta)$ and

$$
l=l(R, \chi, \omega)=\frac{\omega-R}{\eta}+\zeta \chi
$$

When $R, \quad \chi$, and $\omega$ are given, we obtain the $l_{x}, l_{n}$, and $\pi$ as follows:

$$
\begin{gathered}
l_{x}=\alpha \zeta \chi, \\
l_{n}=\frac{\omega-R}{\eta}+\frac{\zeta}{\phi} \chi \\
\pi=\pi(R, \chi, \omega)=\omega-\frac{1}{\alpha \phi} \eta l_{n} .
\end{gathered}
$$

$\phi$ and $v$ were defined as $\phi \equiv 1 /(1-\alpha)$ and $v \equiv 1 /(1-\zeta)$. 


\subsection{Balanced Growth Path}

If the law of motion (11) through (13) has fixed points, they are derived as follows:

$$
R^{*}=\theta+\rho, \quad \omega^{*}=\theta, \quad \chi^{*} \equiv \chi^{*}\left(l^{*}\right), \quad l^{*}>\underline{l} \equiv \alpha \phi \frac{\rho}{\eta},
$$

where $\chi^{*}\left(I^{*}\right)$ is the increasing function of $l^{*}$ defined as $\chi^{*}\left(l^{*}\right)=\left(l^{*} / \zeta\right)+[\rho /(\zeta \eta)]$. $l^{*}$ is determined by the following wage version of the long-run Phillips curve:

$$
\omega^{*}=\Omega\left(l^{*}\right) \equiv \frac{v}{\gamma \rho}\left[\delta_{l}\left(l^{*}\right)^{1+\psi}-\frac{l^{*}}{\chi^{*}\left(l^{*}\right)}\right] .
$$

The steady-state values of $l_{x}$ and $l_{n}$ are

$$
l_{x}^{*}\left(l^{*}\right)=\alpha l^{*}+\alpha \frac{\rho}{\eta}, \quad l_{n}^{*}\left(l^{*}\right)=\frac{l^{*}}{\phi}-\alpha \frac{\rho}{\eta} .
$$

However, to guarantee that $l_{n}^{*}$ is positive, $l^{*}$ must be greater than $\underline{l}$.

If it is the case that $l^{*}>\underline{l}$, at this fixed point $y$ and $N$ grow at constant rates. That is, the economy achieves balanced growth. We shall define this steady state as the balanced growth path (BGP). From (4) and (6), the balanced-growth rate of output is derived as $g_{y}^{*}\left(l^{*}\right)=\left[\eta l_{n}^{*}\left[l^{*}\right]\right] /(\alpha \phi)$. From (17), the inflation rate along the BGP is given by the difference between the money growth rate and the long-run growth rate; that is, $\pi^{*}=\theta-g_{y}^{*}\left(l^{*}\right)$.

\subsection{Natural Employment Level}

We refer to the output and employment level in the flexible-price economy (i.e., when $\gamma=0)$ as the natural output level and the natural employment level. The employment gap is the difference between the actual and natural employment levels. In the flexible-price economy, the employment level, $l$, is characterized by (10) instead of NKPC (9). Then, substituting (4), (19), $w=\alpha N^{\frac{1-\alpha}{\alpha}}$ and $y=c$ into (10), we obtain the natural employment level along the BGP, $\tilde{l}$, as the root of the following implicit function:

$$
\frac{\tilde{l}}{\chi^{*}(\tilde{l})}-\delta_{l}(\tilde{l})^{1+\psi}=0 .
$$

\subsection{Existence and Uniqueness of the Balanced Growth Path}

\subsubsection{Case of Non-Negative Money Growth}

When $\theta \quad\left(=\omega^{*}\right)$ belongs to $[0, \infty)$, the long-run Phillips curve (18) is upward sloping on a $\left(l^{*}, \omega^{*}\right)$-plane as shown in Figure 1 . Note that the horizontal axis measures the employment level instead of the unemployment rate or the employment gap since we focus on the employment level rather than the unemployment rate in this study. Therefore, the usual Phillips curve is flipped backward in Figure 1. 


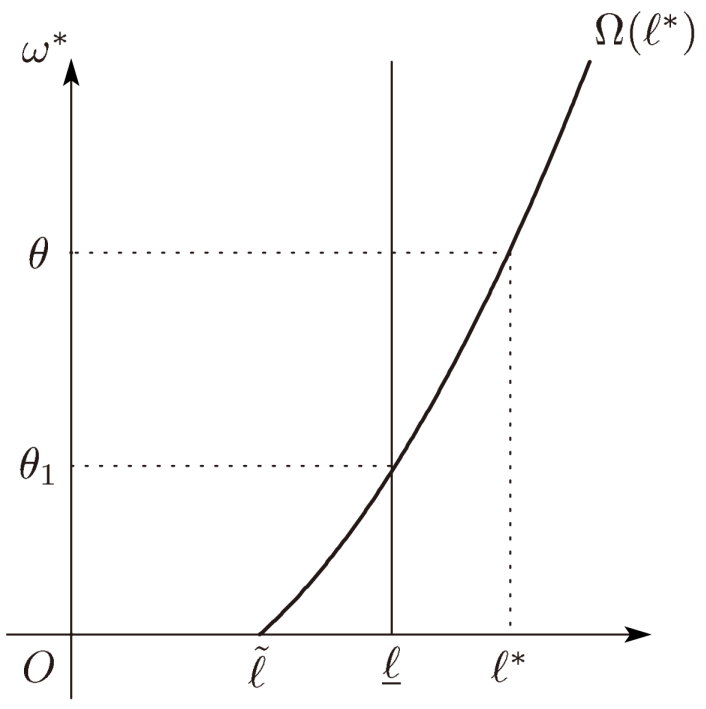

Figure 1. The long-run Phillips curve at the BGP (for $\theta>0$ ).

When $\theta \geq 0$ is given, the BGP level of employment, $l^{*}$, is uniquely determined according to the long-run Phillips curve. However, for a small value of $\theta$, the root of the equation, $\theta=\Omega(l)$, is smaller than $\underline{l}$; it is inappropriate for the BGP value. This threshold is given by

$$
\theta_{1} \equiv \frac{v}{\gamma \rho}\left[\delta_{l}\left(\alpha \phi \frac{\rho}{\eta}\right)^{1+\psi}-\alpha \zeta\right] .
$$

These results may be summarized as follows:

Proposition 1. Let $\theta \geq 0$. If and only if $\theta>\theta_{1}$, a unique $B G P,\left(R^{*}, \chi^{*}\left(I^{*}\right), \omega^{*}\right)$, exists. On the other hand, if $\theta \leq \theta_{1}$, there is no $B G P$.

When the $\mathrm{R} \& \mathrm{D}$ sector is sufficiently productive and the parameters satisfy

$$
\eta>\eta_{0} \equiv \alpha \phi \rho\left(\frac{\alpha \zeta}{\delta_{l}}\right)^{-\frac{1}{1+\psi}},
$$

$\theta_{1}<0$ holds; thus, $\theta \geq 0>\theta_{1}$ always holds. In this case, when the financial authorities apply a monetary policy with $\theta=0, l^{*}=\tilde{l}$ holds and the employment gap caused by nominal wage stickiness is eliminated.

If $\eta \leq \eta_{0}$, the existence of the BGP requires that the money growth rate, $\theta$, is sufficiently high. When $\theta$ is small and the BGP does not exist, there is only the nogrowth steady state mentioned below.

\subsubsection{Case Allowing Money Contraction}

Some algebra shows that $\Omega(0)=0, \Omega^{\prime}(0)<0$ and $\Omega^{\prime \prime}(l)>0, \forall l>0$. Therefore, when we allow a negative value of $\theta, \Omega(l)$ is convex and a unimodal form through the origin as shown in Figure 2. However, $\theta$ is bounded by $-\rho$ to guarantee that the BGP value of the nominal interest rate, $R^{*}=\theta+\rho$, is positive.

When the parameters satisfy 


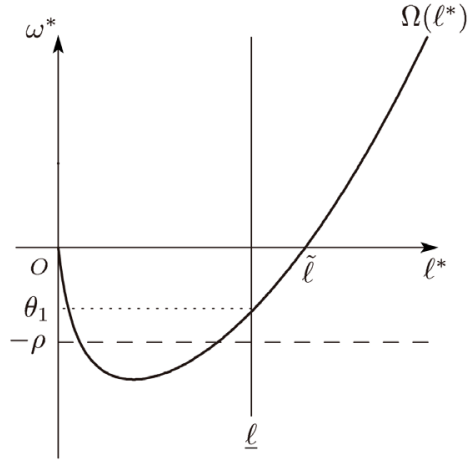

(a)

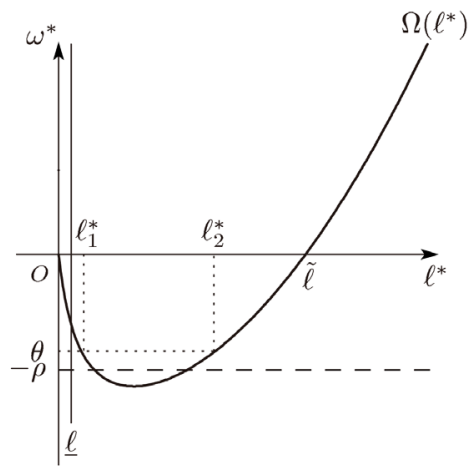

(c)

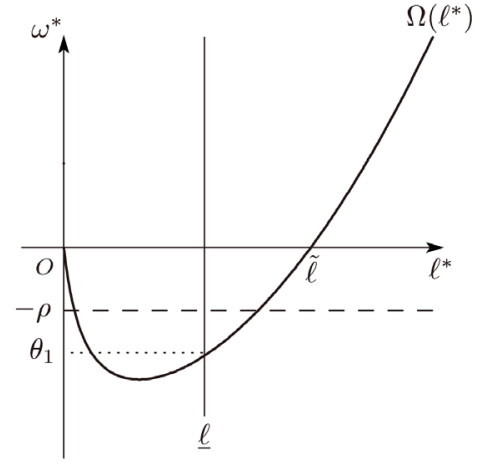

(b)

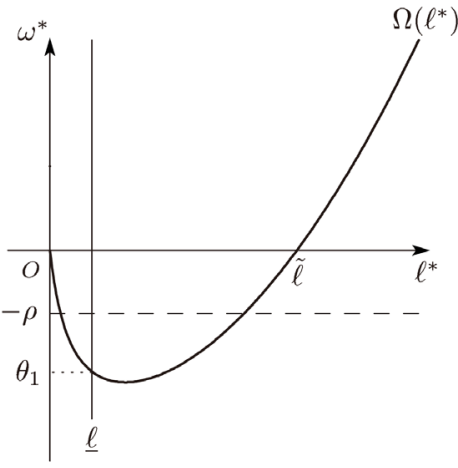

(d)

Figure 2. The long-run Phillips curve at the BGP (for $\theta>-\rho$ ). (a) $\eta<\min \left\{\eta_{1}, \eta_{2}\right\}$; (b) $\eta_{2}>\eta>\eta_{1} ;$ (c) $\left[\eta_{1}>\eta>\eta_{2} ;\right.$ (d) $\eta>\max \left\{\eta_{1}, \eta_{2}\right\}$.

$$
\eta<\eta_{2} \equiv \alpha \phi \rho\left[\frac{\alpha \zeta}{\delta_{l} \phi(1+\psi)}\right]^{-\frac{1}{1+\psi}},
$$

$\Omega^{\prime}(\underline{l})>0$ [see Figure 2(a) and Figure 2(b)]. In contrast, for $\eta>\eta_{2}, \Omega^{\prime}(\underline{l})<0$ holds [see Figure 2(c) and Figure 2(d)]. Moreover, if the parameters satisfy

$$
\eta<\eta_{1} \equiv \begin{cases}\alpha \phi \rho\left[\frac{1}{\delta_{l}}\left(\alpha \zeta-\frac{\gamma \rho^{2}}{v}\right)\right]^{-\frac{1}{1+\psi}}, & \text { if } \alpha \zeta v>\gamma \rho^{2}, \\ \infty, & \text { otherwise, }\end{cases}
$$

$\theta_{1}$ is greater than $-\rho$ [see Figure 2(a) and Figure 2(c)]. For $\eta>\eta_{1}, \theta_{1}<\rho$ holds [see Figure 2(b) and Figure 2(d) $]^{5}$. To sum up these findings, we can see four cases as shown in Figures 2(a)-(d) .

At first, in the cases of Figure 2(b) and Figure 2(d), $\theta=\Omega(l)$ has a unique root such that $l=l^{*}>\underline{l}$ for all $\theta>-\rho$. That is, a unique BGP exists for all possible money growth rates.

In the case of Figure 2(a), $\theta>\theta_{1}$ is again a necessary and sufficient condition for ${ }^{5} \eta_{0}$ is smaller than both of $\eta_{1}$ and $\eta_{2}$.

${ }^{6}$ If $\alpha \zeta v \geq \gamma \rho^{2}$ holds, $\eta_{1}=\infty$ and the cases of Figure 2(b) and Figure 2(c) cannot arise. 
the existence of a unique BGP. That is, sufficiently high rates of money growth are required to achieve sustained economic growth.

The following proposition summarizes the above properties.

\section{Proposition 2.}

1. If the parameters satisfy $\eta>\eta_{1}$, a unique BGP, $\left(R^{*}, \chi^{*}\left(I^{*}\right), \omega^{*}\right)$, exists for all $\theta>-\rho$.

2. Let the parameters satisfy $\eta<\min \left\{\eta_{1}, \eta_{2}\right\}$. If and only if $\theta>\theta_{1}(>-\rho)$, a unique BGP, $\left(R^{*}, \chi^{*}\left(l^{*}\right), \omega^{*}\right)$, exists. In contrast, if $\theta \in\left(-\rho, \theta_{1}\right]$, there is no BGP.

On the other hand, in the case of Figure 2(c), it is possible that $\theta=\Omega(l)$ has dual roots, $l_{1}^{*}$ and $l_{2}^{*}$, which belong to $(\underline{l}, \infty)$ under a contractionary monetary policy. To put it more precisely, we can state the following proposition.

Proposition 3. Let $\eta \in\left(\eta_{2}, \eta_{1}\right)$ hold. For $\theta \geq \theta_{1}$, a unique BGP, $\left(R^{*}, \chi^{*}\left(l^{*}\right), \omega^{*}\right)$, exists. For $\theta<\theta_{1}$ close enough to $\theta_{1}$, dual BGPS, $\left(R^{*}, \chi^{*}\left(l_{1}^{*}\right), \omega^{*}\right)$ and $\left(R^{*}, \chi^{*}\left(l_{2}^{*}\right), \omega^{*}\right)$, exist.

Letting $l_{1}^{*}<l_{2}^{*}$, we obtain $g_{y}^{*}\left(l_{1}^{*}\right)<g_{y}^{*}\left(l_{2}^{*}\right)$. Therefore, when the money growth rate, $\theta$, is smaller than $\theta_{1}(<0)$ and belongs to the neighborhood of $\theta_{1}$, BGPs with a high and low growth rate coexist. Our model has no mechanism to choose between them. That is, global indeterminacy arises. The behavior of the economy is determined by agents' expectations. If the minimum value of $\Omega(l)$ is greater than $-\rho$, by decreasing $\theta$ toward $-\rho$, a saddle-node bifurcation will occur and the BGPs will vanish.

The arguments of Propositions 1 through 3 are summarized in Table 1 for the case of $\eta_{2}<\eta_{1}<\infty$.

\subsection{Money Growth, Inflation, and Economic Growth}

Let a unique BGP exist. Then, we obtain the following proposition.

Proposition 4. Let $\theta>\max \left\{-\rho, \theta_{1}\right\}$ hold and a unique BGP exists. In response to a permanent increase in the money growth rate, $\theta$, the economy experiences greater employment and faster economic growth along the unique BGP.

This proposition can be proved as follows. As shown in Figure 1 and Figure 2, when a unique BGP exists, $l^{*}$ lies on the upward-slope of the long-run Phillips curve. There-

Table 1. The existence and uniqueness of BGP $\left(\eta_{2}<\eta_{1}<\infty\right)$.

\begin{tabular}{cccc}
\hline & $\theta<\theta_{1}$ & $\theta=\theta_{1}$ & $\theta>\theta_{1}$ \\
\hline$\eta \leq \eta_{2}$ & no BGP & no BGP & a unique BGP \\
$\eta \in\left(\eta_{2}, \eta_{1}\right)$ & dual BGPs or no BGP & a unique BGP & a unique BGP \\
$\eta>\eta_{1}$ & - & - & a unique BGP \\
\hline
\end{tabular}

Note: “-" shows that no such combinations of parameters exist because $\theta_{1}<-\rho$.

${ }^{7}$ When $\gamma$ is sufficiently large and the parameters satisfy $\gamma>\alpha \zeta v(\psi+\alpha) /\left[(1+\psi) \rho^{2}\right], \quad \eta_{1}>\eta_{2}$ holds. 
fore, an increase in $\theta$ raises the BGP level of employment, $l^{*}$. Since $\left(l_{x}^{*}\right)^{\prime}\left(l^{*}\right)>0$ and $\left(l_{n}^{*}\right)^{\prime}\left(l^{*}\right)>0$, an increase in $l^{*}$ raises labor allocated to each sector ${ }^{8}$. As a result, since $\left(g_{y}^{*}\right)^{\prime}\left(l^{*}\right)>0$, the greater value of $\theta$ raises $g_{y}^{*}$. That is, economic growth accelerates with money growth ${ }^{9}$.

Furthermore, consider the following two facts. First, the growth acceleration effect of money growth is attributed purely to nominal wage stickiness. A small value of $\gamma$ diminishes the impact of money growth on employment and economic growth. In a flexible-price economy, a change in the money growth rate has no effect on employment and economic growth. That is, money is super neutral ${ }^{10}$. Second, even if financial authorities add $1 \%$ to the money growth rate, the rise in the long-run inflation rate is smaller than $1 \%$ because of the rise in the long-run growth rate $g_{y}^{*}$. That is, the impact of money growth on the long-run inflation rate is weakened by endogenizing growth. Moreover, for high productivity $\mathrm{R} \& \mathrm{D}$, which is captured by large values of $\eta$, the inflation rate might even decrease.

As for dual BGPs, we can prove the following proposition in a similar way to that of Proposition 4.

Proposition 5. Let dual BGPs exist. At the BGP with lower employment level, an increase in the money growth rate raises employment and the balanced-growth rate. Whereas, at the BGP with a higher employment level, an increase in the money growth rate depresses employment and the balanced-growth rate.

\subsection{No-Growth Steady State}

There exists a different steady state from the BGP at which no labor is allocated to R \& $\mathrm{D}$ and long-run growth never occurs. We refer to such a steady state as the no-growth steady state. At the no-growth steady state, since the free-entry condition (7) does not hold with an equality, (14), (15), and (16) are not fulfilled, and $l_{n}=0$ and $l=l_{x}$ hold instead of them.

The value of each variable at this steady state is derived as follows: ${ }^{11}$

$$
R^{0}=\theta+\rho, \quad \pi^{0}=\omega^{0}=\theta, \quad \chi^{0}=\frac{l_{x}^{0}}{\alpha \zeta}, \quad l^{0}=l_{x}^{0}=\left[\frac{1}{\delta_{l}}\left(\frac{\gamma \theta \rho}{v}+\alpha \zeta\right)\right]^{\frac{1}{1+\psi}} .
$$

If and only if $\theta \leq \theta_{1}$, the no-growth steady state, $\left(R^{0}, \chi^{0}, \omega^{0}\right)$, exists ${ }^{12}$. When $\theta \leq \theta_{1}$ and there is no BGP, the no-growth steady state, $\left(R^{0}, \chi^{0}, \omega^{0}\right)$, is a unique steady state of the economy. If two BGPs exist as shown in Proposition 3, there are three steady states in all, and global indeterminacy arises among them.

${ }^{8}$ In addition, $l_{n} / l_{x}$ increases.

${ }^{9}$ It is more realistic to assume the upper limit of labor supply. This study focuses on the situation in which employment does not reach the upper limit of labor supply.

${ }^{10}$ This result depends on the assumption of the money-in-utility-function.

${ }^{11}$ When $\theta$ is negative, $\gamma$ must be sufficiently small and satisfy $\gamma<-\alpha \zeta v /(\theta \rho)$ to obtain the steady state with the positive labor supply.

${ }^{12}$ For $\theta>\theta_{1}, \quad l_{x}^{0}$ is greater than $\underline{l}$, and the free-entry condition (7) is not fulfilled. From (3) and (8), $\dot{V} / V=\omega^{0}=\theta$ and $V=\Pi / \rho$ hold at this steady state, and substituting the latter equation into (7) yields $l_{x}^{0} \leq \underline{l}$. 


\section{Conclusions}

This study developed a R \& D-based endogenous growth model by introducing money growth and a price adjustment process. This study assumed that nominal wage is adjusted stickily because of adjustment cost and derived the new Keynesian Phillips curve, under which money is not super neutral even in the long-run.

When the money growth rate is sufficiently high, the economy has a unique balanced growth path, and can sustain long-run positive growth based on sustained R \& D. Furthermore, faster money growth brings greater employment and faster economic growth along a unique balanced growth path. In contrast, under some parameter restrictions, when the money growth rate is sufficiently low, there is no balanced growth path, and the economy is trapped in a no-growth steady state. These results suggest that money growth may be an important factor for long-run economic growth.

To highlight the effect of nominal wage stickiness, this study adopted the money-inutility-function approach, under which money is supernatural in a flexible-price economy. One interesting extension would be to analyze a model with another specification for money demand, for example cash-in-advance approach. In such case, the super neutrality of money may not hold even in a flexible-price economy, and the growth acceleration effect which is argued in this study might be weakened or strengthened. Such topic will be the subject of future research.

\section{Acknowledgements}

We thank the Editor and the referee for their comments. This paper is a part of the outcome of research performed under a Waseda University Grant for Special Research Projects (Project number: 2015B-014).

\section{References}

[1] Kocherlakota, N. (2016) Fragility of Purely Real Macroeconomic Models. NBER Working Paper No. 21866.

[2] Inoue, T. and Tsuzuki, E. (2011) A New Keynesian Model with Technological Change. Economics Letters, 110, 206-208. http://dx.doi.org/10.1016/j.econlet.2010.11.020

[3] Tsuzuki, E. and Inoue, T. (2010) Policy Trade-Off in the Long Run: A New Keynesian Model with Technological Change and Money Growth. Economic Modeling, 27, 943-950. http://dx.doi.org/10.1016/j.econmod.2010.05.009

[4] Marquis, M.H. and Reffett, K.L. (1991) Real Interest Rates and Endogenous Growth in a Monetary Economy. Economics Letters, 37, 105-109. http://dx.doi.org/10.1016/0165-1765(91)90115-2

[5] Marquis, M.H. and Reffett, K.L. (1995) The Inflation Tax in a Convex Model of Equilibrium Growth. Economica, 62, 109-121. http://dx.doi.org/10.2307/2554778

[6] Jones, L.E. and Manuelli, R.E. (1995) Growth and the Effects of Inflation. Journal of Economic Dynamics and Control, 19, 1405-1428. http://dx.doi.org/10.1016/0165-1889(94)00835-6

[7] Pecorino, P. (1995) Inflation, Human Capital Accumulation and Long-Run Growth. Journal of Macroeconomics, 17, 533-542. http://dx.doi.org/10.1016/0164-0704(95)80067-0 
[8] Mino, K. (1997) Long-Run Effects of Monetary Expansion in a Two-Sector Model of Endogenous Growth. Journal of Macroeconomics, 19, 635-655.

http://dx.doi.org/10.1016/S0164-0704(97)00034-7

[9] Mino, K. and Shibata, A. (1995) Monetary Policy, Overlapping Generations, and Patterns of Growth. Economica, 62, 179-194. http://dx.doi.org/10.2307/2554902

[10] Mino, K. and Shibata, A. (2000) Growth and Welfare Effects of Monetary Expansion in an Overlapping-Generations Economy. Japanese Economic Review, 51, 407-430. http://dx.doi.org/10.1111/1468-5876.00160

[11] Annicchiarico, B., Pelloni, A. and Rossi, L. (2011) Endogenous Growth, Monetary Shocks and Nominal Rigidities. Economics Letters, 113, 103-107.

http://dx.doi.org/10.1016/j.econlet.2011.06.009

[12] Annicchiarico, B. and Rossi, L. (2013) Optimal Monetary Policy in a New Keynesian Model with Endogenous Growth. Journal of Macroeconomics, 38, 274-285.

http://dx.doi.org/10.1016/j.jmacro.2013.10.001

[13] Vaona, A. (2012) Inflation and Growth in the Long Run: A New Keynesian Theory and Further Semiparametric Evidence. Macroeconomic Dynamics, 16, 94-132. http://dx.doi.org/10.1017/s1365100510000453

[14] Tsuzuki, E. and Inoue, T. (2011) Technological Change and Monetary Policy in a StickyPrice Model. Research in Economics, 65, 180-194. http://dx.doi.org/10.1016/j.rie.2010.08.001

[15] Fischer, S. (1993) The Role of Macroeconomic Factors in Growth. Journal of Monetary Economics, 32, 485-512. http://dx.doi.org/10.1016/0304-3932(93)90027-d

[16] Barro, R.J. (1995) Inflation and Economic Growth. Annals of Economics and Finance, 14, 121-144.

[17] Barro, R.J. (1996) Inflation and Growth. Federal Reserve Bank of St Louis Review, 78, 153169.

[18] Levine, R. and Zervos, S.J. (1993) What We Have Learned about Policy and Growth from Cross-Country Regressions? The American Economic Review Papers and Proceedings, 83, 426-430.

[19] Ericsson, N.R., Irons, J.S. and Tryon, R.W. (2001) Output and Inflation in the Long Run. Journal of Applied Econometrics, 16, 241-253. http://dx.doi.org/10.1002/jae.614

[20] Bruno, M. and Easterly, W. (1998) Inflation Crises and Long-Run Growth. Journal of Monetary Economics, 41, 3-26. http://dx.doi.org/10.1016/S0304-3932(97)00063-9

[21] McCandless, J.G.T. and Weber, W.E. (1995) Some Monetary Facts. Federal Reserve Bank of Minneapolis Quarterly Review, 19, 2-11.

[22] Aleskerov, F. and Alper, E.C. (2000) A Clustering Approach to Some Monetary Facts: A Long-Run Analysis of Cross-Country Data. Japanese Economic Review, 51, 555-567. http://dx.doi.org/10.1111/1468-5876.00170

[23] Pollin, R. and Zhu, A. (2006) Inflation and Economic Growth: A Cross-Country Nonlinear Analysis. Journal of Post Keynesian Economics, 28, 593-614. http://dx.doi.org/10.2753/PKE0160-3477280404

[24] Remer, S., Bick, A. and Nautz, D. (2013) Inflation and Growth: New Evidence from a Dynamic Panel Threshold Analysis. Empirical Economics, 44, 861-878. http://dx.doi.org/10.1007/s00181-012-0553-9

[25] Villavicencio, A. and Mignon, V. (2011) On the Impact of Inflation on Output Growth: Does the Level of Inflation Matter? Journal of Macroeconomics, 33, 455-464.

http://dx.doi.org/10.1016/j.jmacro.2011.02.003 
[26] Lee, C.-C. and Wong, S.Y. (2005) Inflationary Threshold Effects in the Relationship between Financial Development and Economic Growth: Evidence from Taiwan and Japan. Journal of Economic Development, 30, 49-69.

[27] Grossman, G.M. and Helpman, E. (1991) Innovation and Growth in the Global Economy. MIT Press, Cambridge.

[28] Rotemberg, J.J. (1982) Sticky Prices in the United States. Journal of Political Economy, 90, 1187-1211. http://dx.doi.org/10.1086/261117

Submit or recommend next manuscript to SCIRP and we will provide best service for you:

Accepting pre-submission inquiries through Email, Facebook, LinkedIn, Twitter, etc.

A wide selection of journals (inclusive of 9 subjects, more than 200 journals)

Providing 24-hour high-quality service

User-friendly online submission system

Fair and swift peer-review system

Efficient typesetting and proofreading procedure

Display of the result of downloads and visits, as well as the number of cited articles

Maximum dissemination of your research work

Submit your manuscript at: http://papersubmission.scirp.org/ 